\title{
Structural, Optical, Magnetic, Photocatalytic Activity and Related Biological Effects of CoFe204 Ferrite Nanoparticles
}

\section{B. Yalcin}

Bahcesehir University

\section{S. Ozcelik}

Hakkari University

K. Icin

Karadeniz Technical University

K. Senturk

Istanbul Gelsim University

B. Ozcelik

Cukurava University

Lutfi Arda ( $D$ lutfi.arda@bahcesehir.edu.tr)

Bahcesehir University https://orcid.org/0000-0003-0722-3891

\section{Research Article}

Keywords: Ferrites, Co-precipitation technique, Magnetic properties, Photocatalysis, Blood compatibility

Posted Date: February 15th, 2021

DOI: https://doi.org/10.21203/rs.3.rs-164750/v1

License: (9) This work is licensed under a Creative Commons Attribution 4.0 International License. Read Full License 


\title{
Structural, Optical, Magnetic, Photocatalytic Activity and Related Biological Effects of $\mathrm{CoFe}_{2} \mathrm{O}_{4}$ Ferrite Nanoparticles
}

\author{
B. Yalcin ${ }^{1}$, S. Ozcelik ${ }^{2}$, K. Icin $^{3}$, K. Senturk ${ }^{4}$, B. Ozcelik ${ }^{5}$ L. Arda $^{6 *}$
}

${ }^{1}$ Bahcesehir University, Vocational School of Health Services, Department of Medical Laboratory Techniques, 34353, Besiktas, Istanbul, Turkey ${ }^{2}$ Hakkari University, Faculty of Engineering, Department of Food Engineering, 30000, Hakkari, Turkey

${ }^{3}$ Karadeniz Technical University, Faculty of Engineering, Department of Metallurgical and Materials Engineering, Trabzon, Turkey

${ }^{4}$ Istanbul Gelisim University, Faculty of Engineering and Architecture, Department of Mechatronics Engineering, 34310, Istanbul, Turkey

${ }^{5}$ Cukurova University, Faculty of Science\&Letters, Department of Physics, 01330, Adana, Turkey

${ }^{6}$ Bahcesehir University, Faculty of Engineering and Natural Sciences, Department of Mechatronics Engineering, 34353, Besiktas, Istanbul, Turkey

*Corresponding Author: lutfi.arda@eng.bau.edu.tr

\begin{abstract}
The synthesis of magnetic nano-size spinel ferrites has become an important area of research, due to their several potential applications. In this work, $\mathrm{CoFe}_{2} \mathrm{O}_{4}$ nanoparticles were synthesized by the co-precipitation method. Structural, magnetic and photocatalytic properties of cobalt ferrites were analyzed based on their chemical composition considering their biological properties. Structural and morphological properties were investigated by X-ray diffraction analysis (XRD) and SEM respectively. Lattice parameters and cell volumes were calculated from XRD data. SEM images revealed uniform surface morphology and spherical shape of nanoparticles. Magnetization measurements were measured by using Lake Shore 7304 model Vibrating Sample Magnetometer. In hemolytic activity tests, formation of a precipitate with a characteristic black color provided an explicit evidence to the formation of heme-iron complexes. Undesirable hemolytic effect of $\mathrm{CoFe}_{2} \mathrm{O}_{4}$ nanoparticles on human erythrocytes at both concentrations was attributed to the comparatively high amount of reactive oxygen species formed by $\mathrm{CoFe}_{2} \mathrm{O}_{4}$ nanoparticles. The theoretical concentration $\mathrm{C}_{\mathrm{o}}$ (theory) obtained by second-order model $(0.82 \mathrm{mg} / \mathrm{L})$ fit with the experimental value of $\mathrm{C}_{\mathrm{o}}$ (experimental) $(0.95 \mathrm{mg} / \mathrm{L})$ well in photocatalytic activity tests.
\end{abstract}

Keywords: Ferrites; Co-precipitation technique; Magnetic properties; Photocatalysis; Blood compatibility

\section{Introduction}

In recent years, nano-sized metal oxide particles have been widely investigated due to their huge contact area between materials, good mechanical and electrical properties arising from the adjustment of dimensions.

Especially, nano-sized iron oxides have gained extreme attention due to their unique material properties such as high surface/volume ratio, excellent photostability and high quantum yield [1]. They become very popular in the fiels of optics, electronics, chemical sensors, bio-imaging applications and medicine. The ability to control the behavior of the nanomaterials using an external magnetic field leads potential applications including magnetic rezonance imaging, controlled drug delivery and magnetic hyperthermia [2, 3]. Nanoparticles, which are planning to be used for such applications, should have a low-toxic nature, high stability, significant selectivity of accumulation in targeted area and superparamagnetic properties at room temperature [4].

For instance, superparamagnetic particles were found positively responsive towards erythrocytes [5, 6] and some cancer cells such as lung and breast cancer even without immunospecific coatings [7, 8]. Besides iron oxide, binary iron oxides and other iron containing nanomaterials also have magnetic properties which is essential for biomedical applications. Especially, the spinel ferrites have gained considerable scientific and technological interest due to their unique physical and chemical properties as well as their technological applications.

Spinel ferrites can be represented by the formula of $\mathrm{MFe}_{2} \mathrm{O}_{4}$ with a face-centered cubic structure where $\mathrm{M}$ is a divalent cation such as $\mathrm{Co}, \mathrm{Cu}, \mathrm{Ni}, \mathrm{Mn}$ or Fe and commonly synthesized by sol-gel method [9]. Among spinel ferrites, copper ferrite $\left(\mathrm{CuFe}_{2} \mathrm{O}_{4}\right)$ and cobalt ferrite $\left(\mathrm{CoFe}_{2} \mathrm{O}_{4}\right)$ are of great interest from physics, chemistry and biomedical aspects since their excellent chemical and mechanical stability, high magnetocrystalline anisotropy, and high coercivity [10-12].

Improved mechanical hardness and stability of $\mathrm{CoFe}_{2} \mathrm{O}_{4}$ under physiological conditions and tunable superparamagnetic behavior by changing particle size [13] make these nano materials a tough competitor over other magnetic materials such as traditional iron oxides, $\mathrm{Fe}_{3} \mathrm{O}_{4}$ and $\mathrm{Fe}_{2} \mathrm{O}_{3}$. Moreover, undesirable interactions of red blood cells and traditional iron oxides could be prevented by ferrites providing better hemocompatibility [14]. A scientific method to adjust the toxicity of nano-sized materials is to apply biocompatible coatings such as polysiloxane, alginate, citric acid etc. to the surface $[15,16]$. A study by Laznev et al. revealed that, there were no significant difference in the cytotoxicity of $\mathrm{CoFe}_{2} \mathrm{O}_{4}$ and polysiloxane surface coated $\mathrm{CoFe}_{2} \mathrm{O}_{4}$ nanoparticles [17]. $\mathrm{CoFe}_{2} \mathrm{O}_{4}$ nanoparticles were also revealed as promising nanocarriers in controlled drug delivery applications [18]. Cai et al. studied the controlled release of doxorubicyn (an anticancer drug) from three dimensional $\mathrm{CoFe}_{2} \mathrm{O}_{4}$ nanospheres synthesized by hydrothermal method. $\mathrm{CoFe}_{2} \mathrm{O}_{4}$ nanospheres were shown to have a high loading capacity of $88.6 \%$ and a promising drug release capacity of $55 \%$ under alternating magnetic field [19]

It appears from our literature research that, spinel ferrites were introduced as promising materials for especially biomedical applications. However, the interactions between these nano-sized materials and tissues and blood components 
is still an uncompleted issue. Thus, it is still an open question whether these nanomaterials are suitable to be used in vivo applications or cause any undesired interactions between the cells of living tissues. This research reports the synthesis and material properties of $\mathrm{CoFe}_{2} \mathrm{O}_{4}$ nanoparticles together with their blood compatibilities. In this study, we were also concerned about the photo-degradation mechanism of crystal violet by $\mathrm{CoFe}_{2} \mathrm{O}_{4}$ nanoparticles which has not been studied sufficiently.

\section{Experimental procedures}

\subsection{Nanoparticle Synthesis}

In this study, all of spinel ferrites were prepared by the coprecipitation methods. Iron(III) nitrate nonahydrate $\left(\mathrm{FeN}_{3} \mathrm{O}_{9} .9 \mathrm{H}_{2} \mathrm{O}\right)$ and Cobalt(II) nitrate hexahydrate $\left(\mathrm{Co}\left(\mathrm{NO}_{3}\right)_{2} \cdot 6 \mathrm{H}_{2} \mathrm{O}\right)$ were used to fabricate nanocrystalline Co-spinel ferrites. All nitrates used in co-precipitation method are of analytical graded Alfa Aesar. The weights used in experimental runs $\left(\mathrm{FeN}_{3} \mathrm{O}_{9} \cdot 9 \mathrm{H}_{2} \mathrm{O} ; \mathrm{Co}\left(\mathrm{NO}_{3}\right)_{2} \cdot 6 \mathrm{H}_{2} \mathrm{O}\right)$, were determined according to stoichiometry between both ferrite and nitrates. The solution mixture of $0.2 \mathrm{M} \mathrm{FeN}_{3} \mathrm{O}_{9} .9 \mathrm{H}_{2} \mathrm{O}$ and $0.1 \mathrm{M} \mathrm{Co}\left(\mathrm{NO}_{3}\right)_{2} .6 \mathrm{H}_{2} \mathrm{O}$ were dissolved in $100 \mathrm{~mL}$ of deionize water. A few drops of oleic acid (approximately $30 \mu \mathrm{L}$ ) were added to the mixture as surfactant. The solutions were mixed in a continuous mode for 2 hours by Bandaline Sonopuls model ultrasonic homogenizer at $80{ }^{\circ} \mathrm{C}$ in water bath for homogeneous temperature distribution. After $2 \mathrm{~h}$ of stirring, $\mathrm{NaOH}$ was added drop by drop to obtain $\mathrm{pH} 9$ under ultrasonic homogenizer for $1 \mathrm{~h}$. At the end of process, precipitate was obtained. The precipitates were centrifuged five times using distilled water at $5000 \mathrm{rpm}$ for 10 minutes by the NUVE NF400 model. The washed precipitates were dried at $80{ }^{\circ} \mathrm{C}$ under vacuum atmosphere for 8 hours. Calcination process for $\mathrm{CoFe}_{2} \mathrm{O}_{4}$ nano-sized particles were carried out at $500{ }^{\circ} \mathrm{C}$ in air condition for 2 hours.

\subsection{Structural Analysis}

The structure of the $\mathrm{CoFe}_{2} \mathrm{O}_{4}$ nanoparticles were characterized by XRD measurements using a PANalytical X'pert Powder $^{3}$ model X-ray diffractometer device with $\mathrm{CuK} \alpha(\lambda=1.5418)$ radiation at room temperature in the scan range of $2 \theta=10^{\circ}-90^{\circ}$ with a scan speed of $3 \% \mathrm{~min}$ and a step increment of $0.02^{\circ}$. The surface morphologies of precipicated powders were examined by using a scanning electron microscope (SEM) of the Zeiss EVO MA model. Optical properties of the $\mathrm{CoFe} 2 \mathrm{O} 4$ naoparticles was measured by using Shimadzu 2600 UV-Spectrometer with an integrating sphere in 300$1000 \mathrm{~nm}$ wavelength range. Magnetic hysteresis experiments were carried out in a Lake Shore model 7304 Vibrating Sample Magnetometer, operating within the 15-300 K temperature range.

\subsection{Photocatalytic Activity Measurements}

The photocatalytic activity of $\mathrm{CoFe}_{2} \mathrm{O}_{4}$ nanoparticles were investigated by photodegradation of crystal violet $(\mathrm{CV})$ under $254 \mathrm{~nm}$ irradiation. The concentration values of nanoparticle dispersion and crystal violet solution was $1.0 \mathrm{mg} / \mathrm{ml}$ and $2.5 \times 10^{-6} \mathrm{M}$ respectively. Distilled deionized water (DDW) obtained from Human Zeneer Power1 water purification system was used in the experiments. CV solutions containing the appropriate amount of nanoparticles were kept under magnetic stirring for 30 minutes (in darkness) to establish an adsorption/desorption equilibrium of CV molecules on the nanoparticle surface. After 30 minutes, $254 \mathrm{~nm}$ irradiation of CV-nanoparticle suspensions was started under continuous magnetic stirring. Aliquot parts were taken at appropriate time intervals and centrifuged at 4000rpm to precipitate suspended nanoparticles. The absorption maxima of each supernatant was verified using a UV/vis spectrophotometer (Shimadzu UV mini 1240) at a wavelength of $591 \mathrm{~nm}$ corresponding to the absorption maxima of crystal violet. Distilled water was used as reference.

Photocatalytic properties of spinel ferrite nanoparticles were investigated using three different kinetic models namely zero-order, first-order and second order given by equations 1, 2 and 3 [20-22].

Zero-order :

First-order :

$$
\begin{gathered}
C=C_{o}-k t \\
\operatorname{In}\left(\frac{C_{o}}{C}\right)=k_{1} t
\end{gathered}
$$

Second-order:

$$
\frac{1}{C}=\frac{1}{C_{o}}+k_{2} t
$$

where $C_{o}$ and $C$ represent the initial concentration of crystal violet at $\mathrm{t}=0$, and the concentration of crystal violet after a certain irradiation time $(t)$, respectively. $k, k_{l}$ and $k_{2}$ were the rate constants for photocatalytic degradation.

\subsection{Blood Compatibility Tests}

Hemolytic activity of $\mathrm{CoFe}_{2} \mathrm{O}_{4}$ ferrites against human erythrocyte membrane were investigated. $0.108 \mathrm{mM}$ aqueous solution of trisodium citrate was used as stabilizing agent to prevent the coagulation of whole blood samples collected from healthy volunteers. Blood:anticoagulant ratio was adjusted as (9:1). Phosphate buffer solution (PBS) having a pH 
of 7.35 was prepared using $\mathrm{Na}_{2} \mathrm{HPO}_{4} .2 \mathrm{H}_{2} \mathrm{O}(1.78 \mathrm{~g} / \mathrm{L}), \mathrm{KH}_{2} \mathrm{PO}_{4}(0.24 \mathrm{~g} / \mathrm{L}), \mathrm{KCl}(0.2 \mathrm{~g} / \mathrm{L})$ and $\mathrm{NaCl}(8 \mathrm{~g} / \mathrm{L})$ then autoclavesterilized at $1 \mathrm{~atm}$ and $121^{\circ} \mathrm{C}$ for 15 minutes. $\mathrm{Ca}$ and $\mathrm{Mg}$ free phosphate buffer solution was used to dilute the anticoagulated whole blood samples. Red blood cells (RBCs) was separated from plasma by centrifugation at $4000 \mathrm{rpm}$ for 5 minutes. Precipitated RBCs were diluted up to $50 \mathrm{ml}$ by adding PBS. $1.0 \mathrm{mg} / \mathrm{ml}$ and $5.0 \mathrm{mg} / \mathrm{ml}$ concentrations of $\mathrm{CoFe}_{2} \mathrm{O}_{4}$ suspensions were prepared and mixed with $0.8 \mathrm{ml}$ of $\mathrm{RBC}$ stock solution. DDW and PBS were used in positive and negative control tests, respectively. In positive control test DDW cause complete (100\%) hemolysis of all erythrocytes and negative control test corresponds to $0 \%$ hemolysis.

RBCs were incubated in presence of varying nanoparticle concentrations under magnetic stirring at $37^{\circ} \mathrm{C}$ for 3 hours. Each test was performed twice. At the end of the incubation period, the samples were centrifuged at $3000 \mathrm{rpm}$ for 5 minutes and the absorbance value of supernatant was used to quantify the the degree of hemoglobin release into the medium following cell lysis. Percent hemolysis values were calculated using the absorbance (ABS) value at $540 \mathrm{~nm}$ using the equation given below [23].

$\%$ Hemolysis $=\frac{\mathrm{ABS}_{\text {test sample }}-\mathrm{ABS}_{\text {negative control }}}{\mathrm{ABS}_{\text {positive sample }}-\mathrm{ABS}_{\text {negative control }}}$

\section{Results and Discussions}

\subsection{XRD analysis}

The X-ray diffraction (XRD) was used to investigate the crystalline phases of $\mathrm{CoFe}_{2} \mathrm{O}_{4}$ nanoparticles. The XRD of the $\mathrm{CoFe}_{2} \mathrm{O}_{4}$ ferrite nanoparticles was shown in Fig. 1.

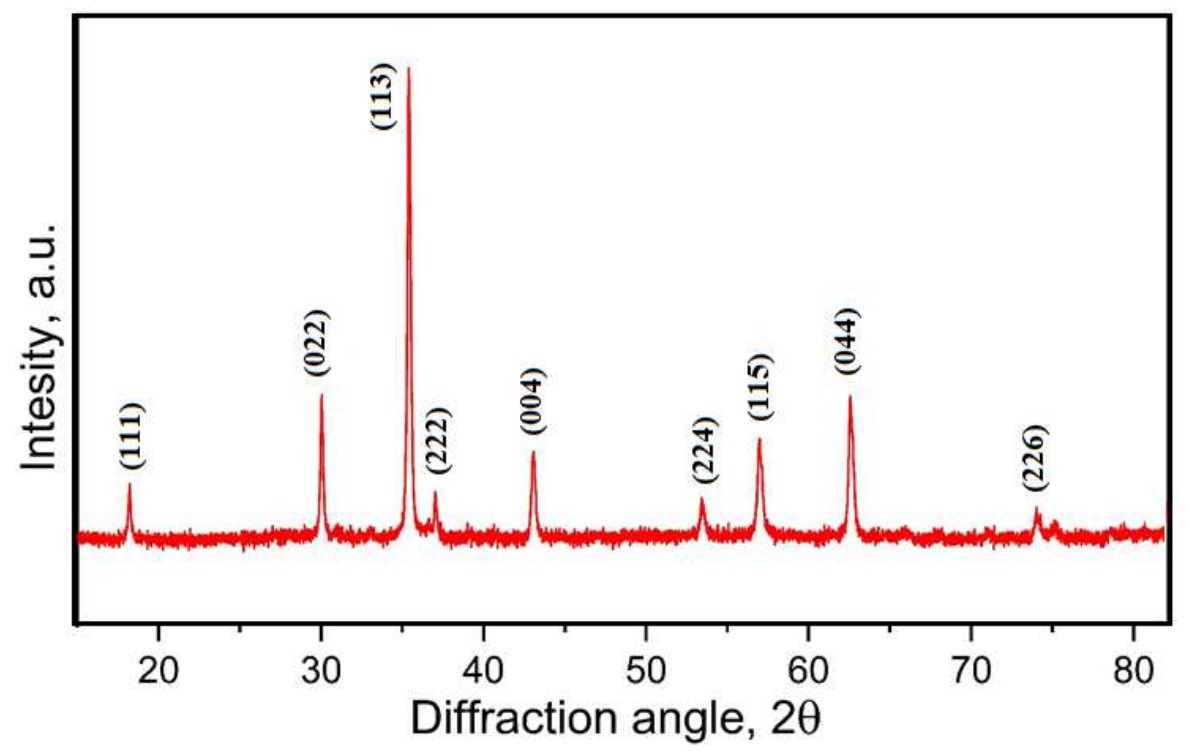

Fig. $1 \mathrm{X}$-ray diffraction patterns of $\mathrm{CoFe}_{2} \mathrm{O}_{4}$ ferrite nanoparticles.

As shown in Fig. 1, it can be seen that $\mathrm{CoFe}_{2} \mathrm{O}_{4}$ nanoparticles are spinel cubic structure without secondary phases which is corresponds to PDF Card No.: 00-003-0875 Quality:B. The lattice parameter, $a$, was calculated from the diffraction pattern by using the Eq. 5 .

$a_{\text {exp }}=d_{h k l}\left(h^{2}+k^{2}+l^{2}\right)^{1 / 2}$

The crystallite size of the $\mathrm{CoFe}_{2} \mathrm{O}_{4}$ nanoparticles was calculated from the full-width at half maximum (FWHM) of the most intense peak (113) using the Debye-Scherrer equation:

$D=0.9 \lambda / \beta \cos \theta_{B}$

where $\lambda$ is the X-ray wavelength of $C u K \alpha, \beta$ is the FWHM of the diffraction peaks, and $\theta_{B}$ is the angle of Bragg diffraction. The calculated crystallite size (D) and lattice parameter ( $a$ ) of $\mathrm{CoFe}_{2} \mathrm{O}_{4}$ nanoparticles for (113) peak were $39.2601 \mathrm{~nm}$ and $8.40 \AA$ respectively.

\subsection{SEM analysis}


The morphology of $\mathrm{CoFe}_{2} \mathrm{O}_{4}$ nanoparticles was studied using Scanning Electron Microscope as shown in Fig. 2. As can be seen from the figure ( $a, b, c$ and $d$ ), the particles do not have a complete shape because they are agglomerated. As the resolution decreases, the structure appears dense and molten (Figs. a and b). On the other hand, as the resolution increases, the structure looks like snowflakes (Fig. 2d). The basic composition of all $\mathrm{CoFe}_{2} \mathrm{O}_{4}$ nanoparticles was provided by the EDS analysis illustrated in Fig. 3. All peaks in EDS analysis belong to $\mathrm{CoFe}_{2} \mathrm{O}_{4}$ nanoparticles. There are no other undesirable extra elemental peak additives.

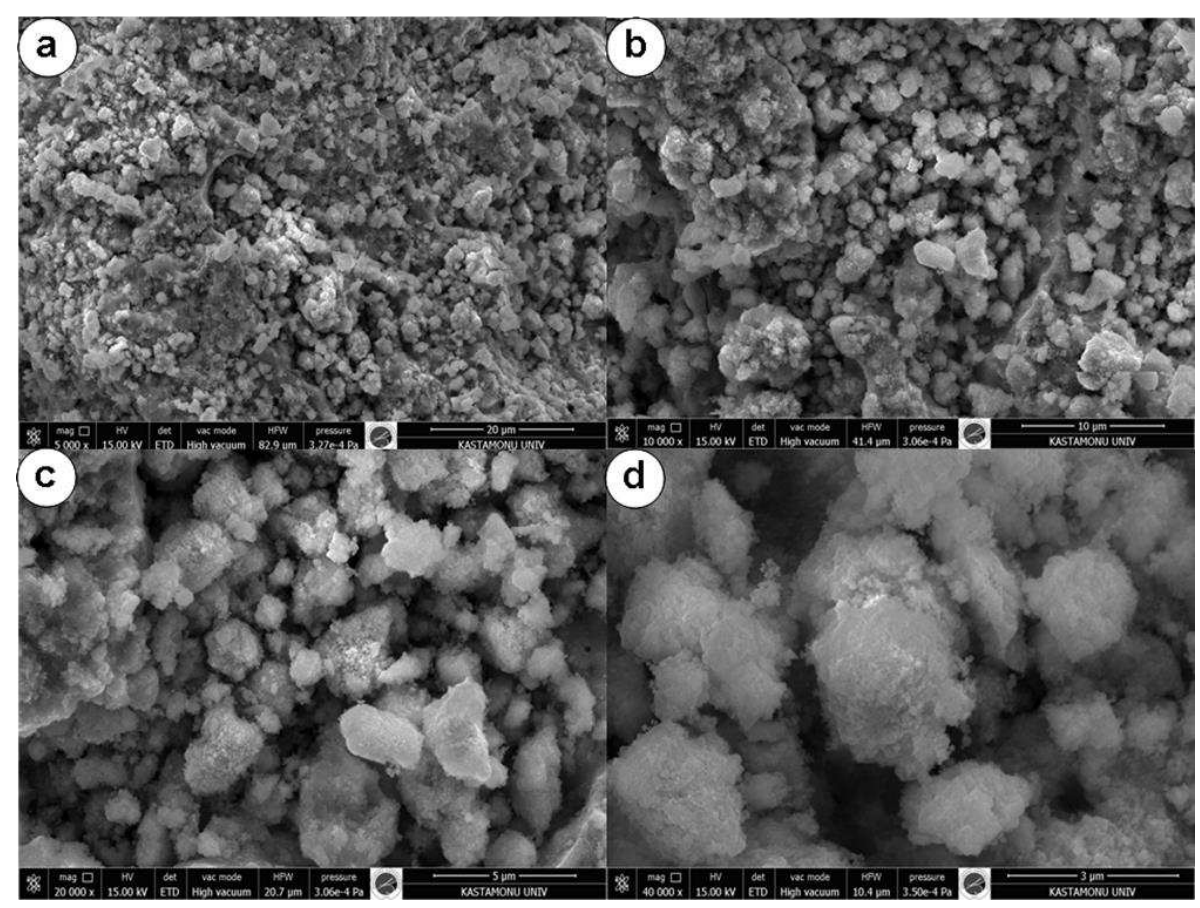

Fig. 2 SEM images of $\mathrm{CoFe}_{2} \mathrm{O}_{4}$ nanoparticles for 20, 10, 5 and $3 \mu$ m magnifications in (a), (b), (c) and (d), respectively.

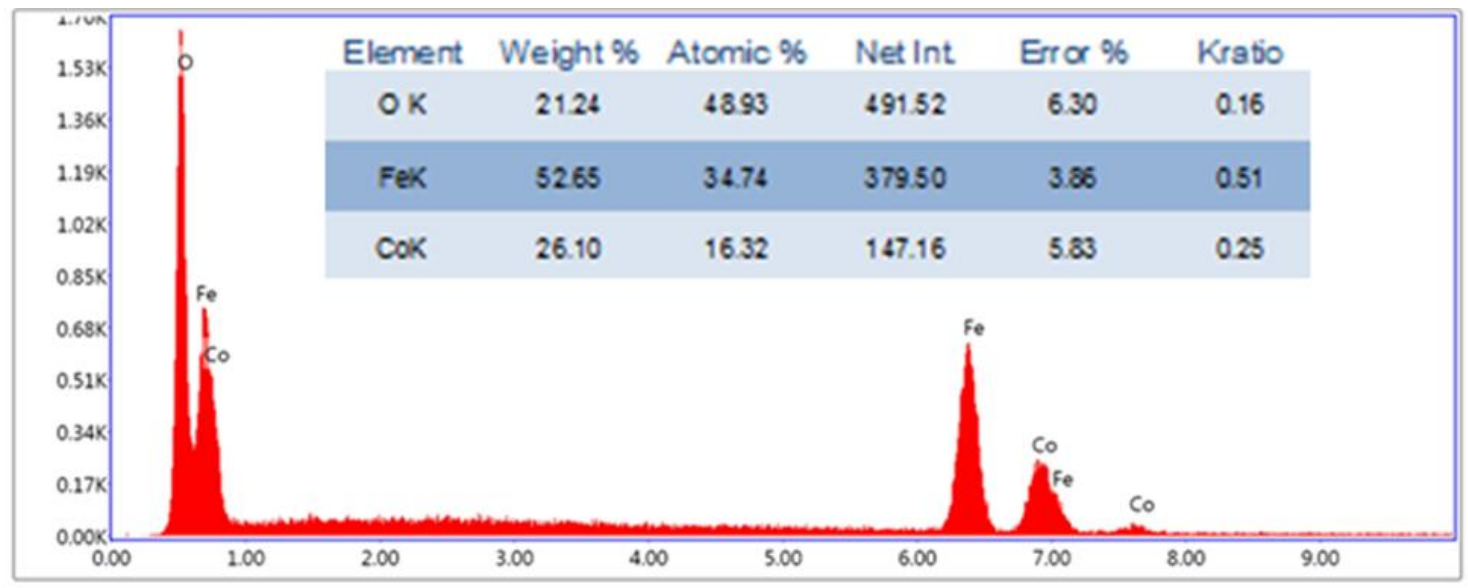

Lsec: $26.60 \mathrm{Cnts} 0.000 \mathrm{keV}$ Det Octane Pro Det

Fig. 3 EDS graph of $\mathrm{CoFe}_{2} \mathrm{O}_{4}$ nanoparticles.

\subsection{Band Gap Calculation}

The reflectance spectra of the $\mathrm{CoFe}_{2} \mathrm{O}_{4}$ nanoparticles, obtained by UV-VIS diffuse reflectance measurements (DRS) within the range of 0-700 nm wavelength. Notice that the graph inset in Fig. 4 has an absorption edge close to $140 \mathrm{~nm}$. The Kubelka-Munk function was used to calculate the reflection ratio $F(R)$, which is proportional to the absorption coefficient $(\alpha)[23]$.

$$
F(R)=\frac{(1-R)^{2}}{2 R}
$$

The following equation can be used to determine the optical band gap Eg for the photon energy (hv) and the absorption coefficient $(\alpha)$ : 


$$
\alpha h \mathrm{v}=\mathrm{k}\left(\mathrm{hv}-E_{g}\right)^{1 / n}
$$

In Eq. (8), $E_{g}$ and $\mathrm{k}$ are the optical band gap and energy-independent constants, respectively. Since $F\left(R_{\alpha}\right)$ is proportional to $\alpha$ and $n$ is a constant that depends on the bandgap type $1 / 2$ and 2 for direct and indirect bandgaps, respectively. Thus, for directly allowed transitions, $n$ is taken as 2 Eq. (8) can be transformed to

$$
F\left(R_{\alpha}\right) h \mathrm{v}=\mathrm{k}\left(\mathrm{hv}-E_{g}\right)^{2}
$$

In other words, $\left(F\left(R_{\alpha}\right) h v\right)^{2}=k^{2}\left(h v-E_{g}\right)$. The slope of the graphs of $\left(F\left(R_{\alpha}\right) h v\right)^{2}$ was approximated by using a linear fit $y(h v)=A \times h v+B$ in the least-squares sense. To accomplish this, the error formula below in Eq. (10)

$$
E(A, B)=\min _{A, B} \sum_{i=1}^{N}\left[A \times(h v)_{i}+B-\left(\left(F\left(R_{\alpha}\right) h v\right)^{2}\right)_{i}\right]^{2}
$$

were minimized for $A$ and $B$ where $N$ is the number of data points. Table 1 displays $A, B$, band gap energies $E_{g}$ and relative error value.

The direct and indirect band gap energy $E_{g}$, as shown in Table 1 and Fig. 4, was calculated by the linear approximation of the slope of the graph of $\left(F\left(R_{\alpha}\right) h v\right)^{2}$ to the photon energy axis where $F\left(R_{\alpha}\right)=0$, namely, $E_{g}=h v=-B / A$, as plotted in Fig. 4. In other words, the intersection between the linear fit and the photon energy axis gave the value to $E_{g}$. The direct gap energies of the Coi-ferrite nanoparticles samples were observed as $2.1 \mathrm{eV}$ as shown in Fig. 4 which was accurate within three decimal digits. The values of Eg depended on several factors including lattice strain, carrier concentration, crystallite size, and the size effect of the dopant metals in Co-ferrite lattice.

Table 1

Calculating direct and indirect band gap energy for nickel ferrite with fitting curve function $y(h v)=A \times h v+B$.

\begin{tabular}{lcccc}
\hline Sample & A & B & E $_{\mathbf{g}}$ & Relative Error \\
\hline $\mathrm{CoFe}_{2} \mathrm{O}_{4}$ & 3.14 & -6.6 & 2.10 & $9.51 \times 10^{-4}$ \\
\hline
\end{tabular}

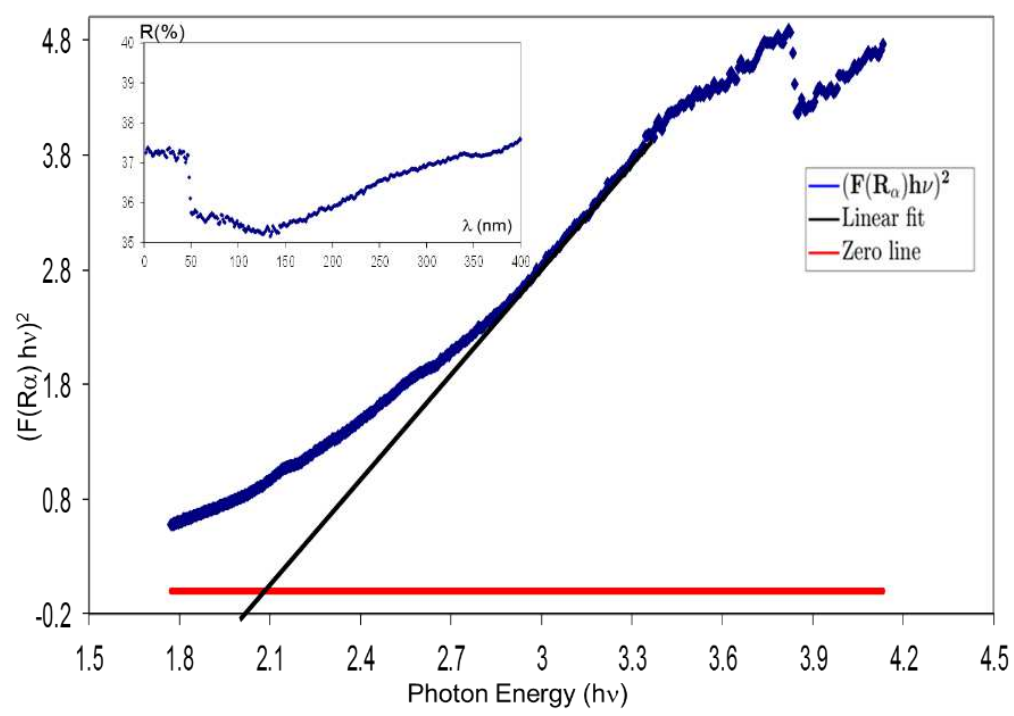

Fig. 4 The plots of $\left(F\left(R_{\alpha}\right) \mathrm{h} v\right)^{2}$ as a function of photon energy (hv) and the linear fit for the $\mathrm{CoFe}_{2} \mathrm{O}_{4}$ nanoparticles.

\subsection{Magnetic behaviour}

Vibrating Sample magnetometer (VSM) was used to characterize the magnetic nature of the $\mathrm{CoFe}_{2} \mathrm{O}_{4}$ nanoparticles. All measurements were taken in the range of $\pm 1 \mathrm{~T}$ at room temperature. The field dependence of magnetization was shown in Fig. 5. As seen in figures, the magnetization curve exhibits a narrow hysteresis. The remanent magnetization $\left(M_{r e m}\right)$ and coercivity field $\left(H_{c}\right)$ values depicted in Table 2, for the nanoparticles. Using the formula below:

$$
M=M_{S}\left[1-\frac{\beta}{H^{2}}\right]
$$

the field dependence of the magnetization (M) close to the saturation value is calculated [24], 
where $M s$ is the saturation magnetization, $\beta$ is a parameter related with the magneto-crystalline anisotropy and $H$ is the applied magnetic field.

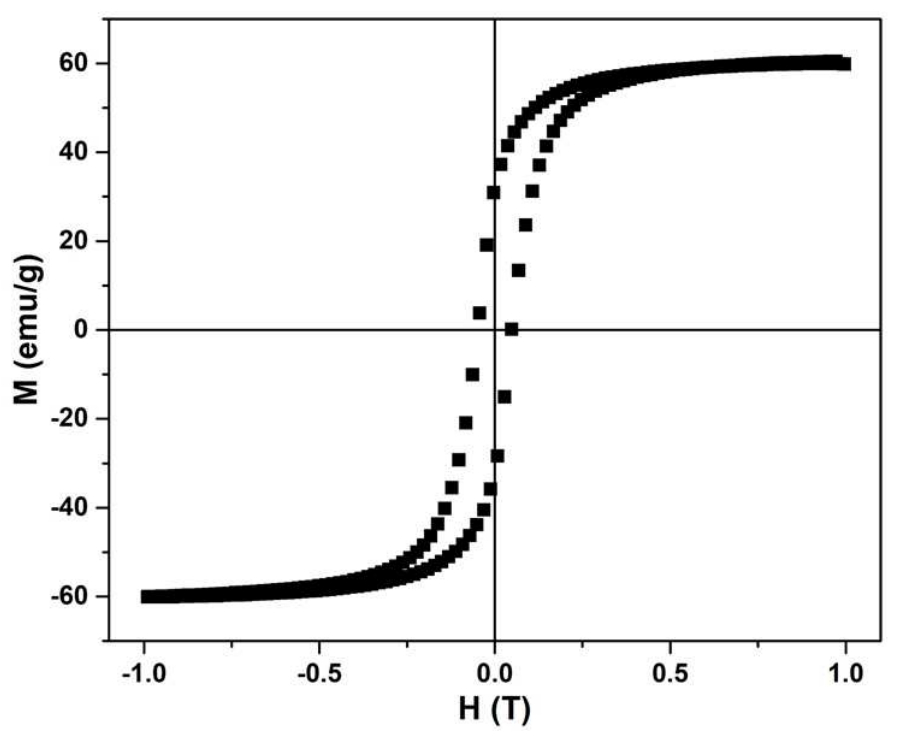

Fig. $5 \mathrm{M}$ - $\mathrm{H}$ curves measured at $\mathrm{T}=300 \mathrm{~K}$ for $\mathrm{CoFe}_{2} \mathrm{O}_{4}$ nanoparticles.

Table 2

Magnetic saturation and coercivity field values of nanoparticles at room temperature.

\begin{tabular}{lllc}
\hline Samples & $\mathbf{H}_{\mathbf{c}}(\mathbf{O e})$ & $\mathbf{M}_{\mathbf{s}}(\mathbf{e m u} / \mathbf{g})$ & $\boldsymbol{\beta}$ \\
\hline $\mathrm{CoFe}_{2} \mathrm{O}_{4}$ & 483 & 60.39 & -0.375 \\
\hline
\end{tabular}

The magnetization versus $1 / H^{2}$ plots were shown in Fig. 6. $\beta$ and $M s$ values of the $\mathrm{CoFe}_{2} \mathrm{O}_{4}$ nanoparticles determined from the slope of the linear fitting and the interception with the $y$-axis, respectively. The obtained values were depicted in Table 2. Once the $\beta$ value is determined, the magnetic anisotropy constant ( $K a$ ) may be conveniently determined using Eq. 12 [24]:

$$
K_{a}=M_{s} \sqrt{\frac{15 \beta}{4}}
$$

The derived $K_{a}$ value at $300 \mathrm{~K}$ is $2.26 * 10^{5} \mathrm{erg} / \mathrm{g}$.

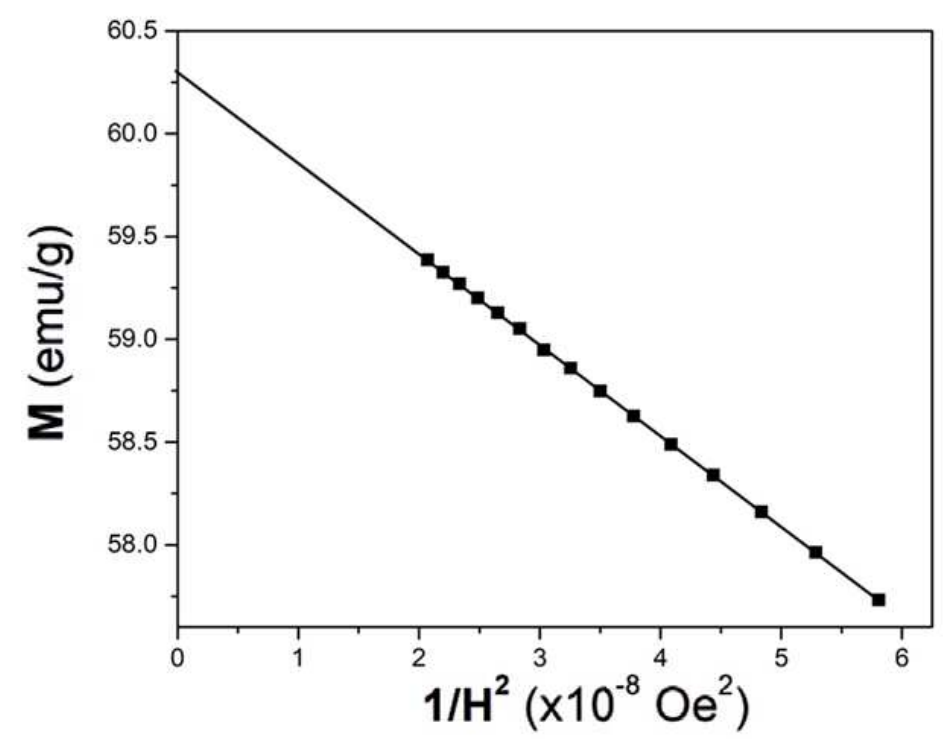

Fig. 6 Plots of $M$ vs. $1 / H^{2}$ obtained on representative samples at T=300 K. 


\subsection{Blood Compatibility Tests}

The synthesis of magnetic nano-size spinel ferrites has become an important area of research, due to their several potential applications [25-28]. Materials planned to be used in medical area must be well tested in terms of their biocompatibility. A hemolytic activity test is a suitable and scientific way of determination of biocompatibility of a synthetic material with living systems [29].

In a related literature study, $\mathrm{CoFe}_{2} \mathrm{O}_{4}$ nanoparticles (30 to $50 \mathrm{~nm}$ ) synthesized by the conventional micro emulsion technique did not recommended to be used in intravenous drug administrations due to the negative findings of complete blood count [30]. However some studies remark the impressive physicochemical properties of $\mathrm{CoFe}_{2} \mathrm{O}_{4}$ nanoparticles like mechanical hardness, improved stability and colloidal dispersibility under physiological conditions. Incompatibility between hemoglobin and iron containing materials arises from the presence of iron in the structure. These undesirable interactions could be prevented using ferrites for better tissue perfusion and hemocompatibility [31].

Nano-sized materials may change the morphology of red blood cells (RBCs or erythrocytes) and cause hemolysis. Hemolysis is defined as the breakdown of cell membrane and lysis of cells. These undesirable interactions between nanoparticles and the blood may promote inflammatory and autoimmune disorders or leading infections as well as cancer by inducing the immune system to suppress [32]. In our study, cobalt ferrites $\left(\mathrm{CoFe}_{2} \mathrm{O}_{4}\right)$ were investigated in terms of their blood compatibility. Human erythrocytes drawn from healthy volunteers were used to investigate the hemolytic potentials of $\mathrm{CoFe}_{2} \mathrm{O}_{4}$ nanoparticles.

Fig. 7 shows the UV-vis spectra of erythrocyte suspensions treated with $\mathrm{PBS}$ alone (control) and $\mathrm{CoFe}_{2} \mathrm{O}_{4}$ nanoparticles with two different concentrations, those are $1.0 \mathrm{mg} / \mathrm{ml}$ and $5.0 \mathrm{mg} / \mathrm{ml}$. Hemolysis ratios correspond to 1.0 $\mathrm{mg} / \mathrm{ml}$ and $5.0 \mathrm{mg} / \mathrm{ml}$ concentrations were $5.4 \%$ and $24.7 \%$ respectively. Hemolysis percentages lower than $5 \%$ are regarded as safe by International Standards Organization [33]. Thus, for both lower and higher concentrations of $\mathrm{CoFe}_{2} \mathrm{O}_{4}$, nanoparticles showed an undesirable hemolytic effect on human erythrocytes. This may be attributed to the comparatively high amount of reactive oxygen species formed by $\mathrm{CoFe}_{2} \mathrm{O}_{4}$ nanoparticles shown in photocatalytic activity tests (Fig. 8). Besides, a sharp increase for the absorption band at $408 \mathrm{~nm}$ corresponds to the strong oxidation of oxyhemoglobin to methemoglobin. Moreover, in $\mathrm{CoFe}_{2} \mathrm{O}_{4}$ test tubes, the precipitate with a characteristic black color provided an explicit evidence to indicate the formation of heme-iron complexes [34] (Fig. 7-inset photos).

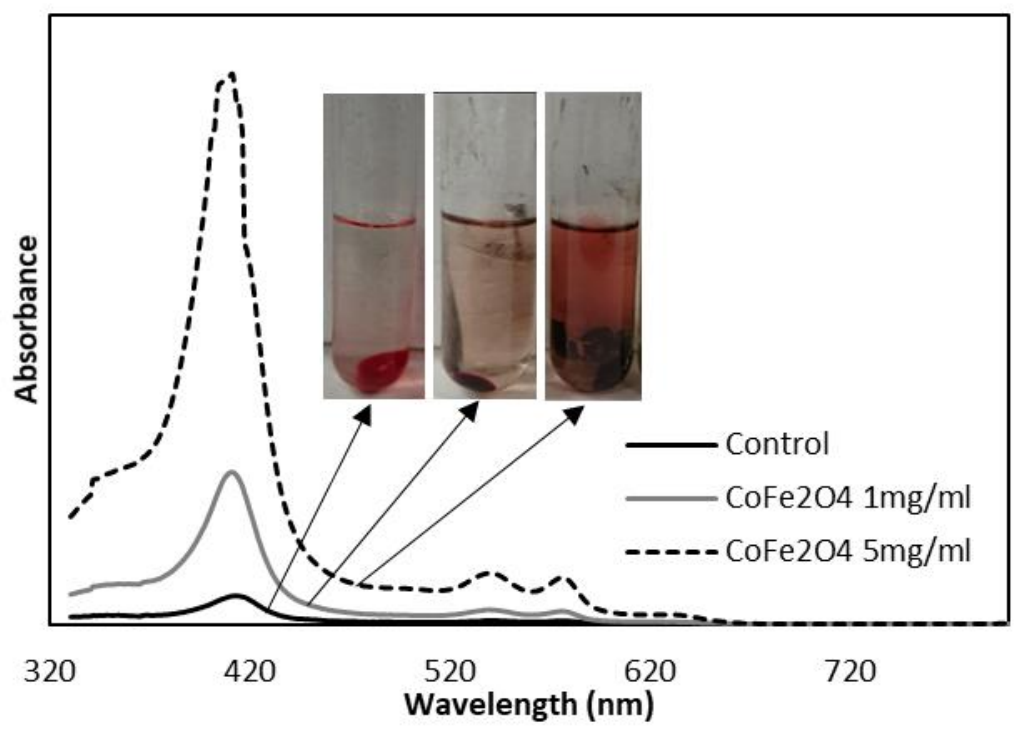

Fig. 7 UV-vis spectra of erythrocyte suspensions treated with PBS alone (control) and $\mathrm{CoFe}_{2} \mathrm{O}_{4}$ nanoparticles with two different concentrations. The inset shows blood supernatant after centrifugation.

Despite of the fact that cobalt is a microelement essential for living organisms as it is the cofactor of cobolamine (vitamin B12), cobalt can have toxic effects at high concentrations. Cobalt compounds are classified as class II, which means they are not extremely toxic. However, cobalt compounds cause defects in protein and carbohydrate metabolisms, anaemia, carcinogenic and mutagenic effects [35]. Cobalt is a potential inducer of oxidative stress causing reactive oxygen species generation [36]. Reactive oxygen species (ROS) cause the oxidation of hemoglobin to methemoglobin (MHb). Methemoglobin forms when the ferrous $\left(\mathrm{Fe}^{2+}\right)$ ions in heme are oxidized to the ferric $\left(\mathrm{Fe}^{3+}\right)$ state, and the molecule will be unable to carry oxygen to tissues. MHb can form either spontaneously or be induced to form by many substances, including chlorites, phenolic compounds and heavy metals such as copper, zinc and cobalt [37-39]. Normally, methemoglobin is reconverted to hemoglobin spontaneously by an enzymatic reduction within the cells. Cobalt may affect this mechanism by blocking the enzymatic activity [40]. Concisely, cobalt induced oxidation of heme and increasing concentration of methemoglobin was observed with increasing $\mathrm{CoFe}_{2} \mathrm{O}_{4}$ concentration. In conclusion, $\mathrm{CoFe}{ }_{2} \mathrm{O}_{4}$ nanoparticles showed undesirable hemolytic effect in both $1 \mathrm{mg} / \mathrm{ml}$ and $5 \mathrm{mg} / \mathrm{ml}$ concentrations. 


\subsection{Photocatalytic Activity Measurements}

Oxidative stress mediates several pathological changes include not only the hemolysis, but also the oxidation of sulfhydryl groups on the globin moiety of hemoglobin leading oxidative denaturation, altered endothelial cell function leading vascular disorders such as hypertension, stroke, and heart infarction etc. [41, 42]. Reactive oxygen species that are responsible for these undesirable pathologies can also be used to degrade organic pollutants such as phenols, aromatic hydrocarbons, dyes or pharmaceuticals in contaminated sources.

Changes in the UV-visible spectra of non-photodegraded CV in presence of $\mathrm{CoFe}_{2} \mathrm{O}_{4}$ nanoparticles with the variation of time and second order kinetic plot for photocatalytic degradation of $\mathrm{CV}$ over $\mathrm{CoFe}_{2} \mathrm{O}_{4}$ nanoparticles were shown in Fig. 8a and 8b. Decreasing absorption maxima at $591 \mathrm{~nm}$ indicated the degradation of $\mathrm{CV}$ by $\mathrm{CoFe}_{2} \mathrm{O}_{4}$ nanoparticles. Intensity of this characteristic band was gradually weakened in the first 420 minutes under the effect of $254 \mathrm{~nm}$ light and indicated the photo-degradation of $\mathrm{CV}$ by $\mathrm{CoFe}_{2} \mathrm{O}_{4}$ nanoparticles.
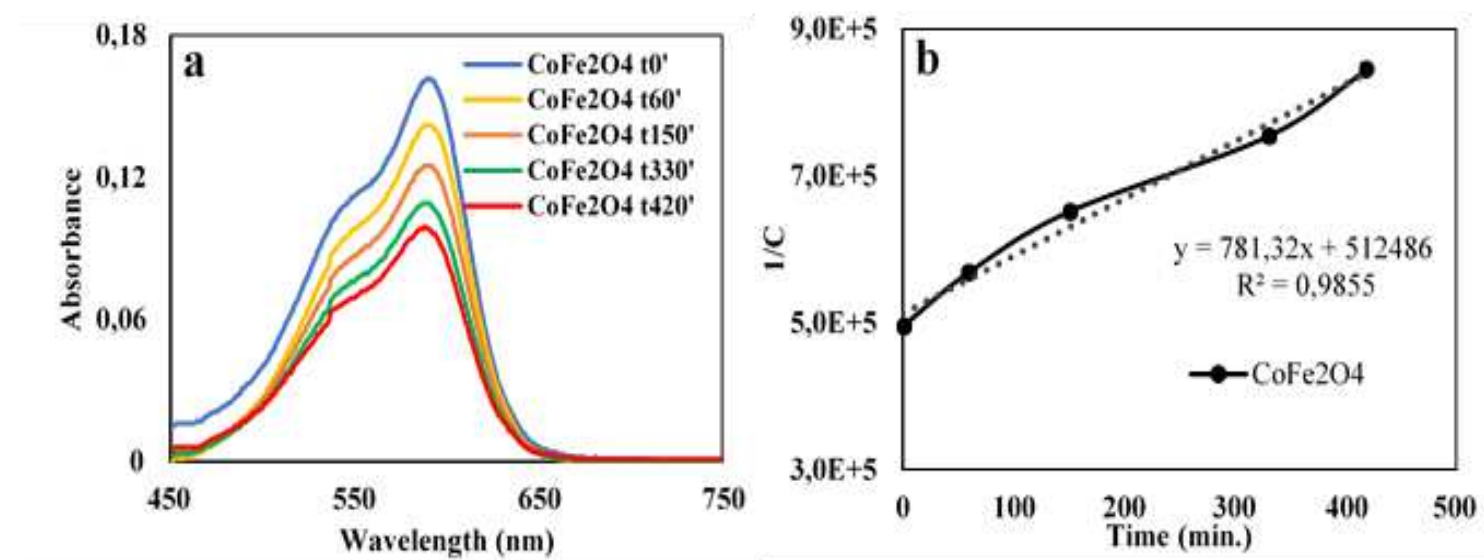

Fig. $8 \mathrm{UV}$-vis spectra of CV as a function of time in presence of (a) $\mathrm{CoFe}_{2} \mathrm{O}_{4}$ under 254 nm irradiation and (b) second order kinetic plot for photocatalytic degradation of $\mathrm{CV}$ over $\mathrm{CoFe}_{2} \mathrm{O}_{4}$ nanoparticles.

In this study, when ferrite nanoparticles were subjected to the $254 \mathrm{~nm}$ irradiation, $\mathrm{Co}^{2+}$ sites were excited with photogenerated electrons and $\mathrm{Co}^{3+}$ ions were produced (Eq. 13). This phenomenon could be a triggering case for the oxidation of iron in hemoglobin where ferrous form turns into ferric form and induce methemoglobin generation (Eq. 14).

Electron-hole pairs generated by radiation on the valence and conduction bands of semiconductors lead to the formation of ROS which are assumed to be responsible for the decomposition of organic molecules [43]. Photocatalytic decomposition mechanism of organic molecules under the effect of electromagnetic radiation has been well defined as an oxidative process in which three major steps were involved. In the fist step of photocatalytic degradation, electrons in valence band were excited by the radiation having energy higher than the band gap of semiconductor. Migration of the excited electrons to an empty conduction band leaves equal number of electron holes $\left(\mathrm{h}^{+}{ }_{\mathrm{vB}}\right)$ in the valence band. Second step is the migration of excited electrons to the surface.

Finally, the photo generated electron-hole pairs take part in redox reactions resulting the formation of reactive oxygen species (ROS). In this last step, photo-generated electrons are trapped by the oxygen and electron holes in the valence band interact with $\mathrm{H}_{2} \mathrm{O}$ resulting the formation of superoxide $\left(\mathrm{O}_{2}{ }^{-*}\right)$ and hydroxyl radicals $\left(\mathrm{OH}^{*}\right)$ respectively (Eq. 15 a and $b$ ). This step is followed by the formation of other reactive intermediates including $\mathrm{H}_{2} \mathrm{O}_{2}$ and hydroperoxyl radical $\left(\mathrm{HOO}^{*}\right)\left((\right.$ Eq. $15 \mathrm{c})$ [44]. Afterwards, photo-generated electrons could be trapped by $\mathrm{O}_{2}$ to form superoxide radicals $\left(\mathrm{O}_{2}{ }^{-*}\right)$, followed by the generation of other radicalic species $\left(\mathrm{O}_{2}{ }^{-*}, \mathrm{HO}^{*}, \mathrm{HO}_{2}{ }^{*}\right)$. Also, the $\mathrm{Co}^{3+}$ sites can react with $\mathrm{OH}^{-}$and return back into $\mathrm{Co}^{2+}$ to complete the photocatalytic circle (Eq. 17) [45]. Finally, the reactive species, including $\mathrm{O}_{2}{ }^{-*}, \mathrm{HO}^{*}, \mathrm{HO}_{2}{ }^{*}$ possess sufficient energy for the photocatalytic degradation of CV (Eq. 18).

$$
\begin{aligned}
& \mathrm{Co}^{2+}+\mathrm{hv} \rightarrow \mathrm{Co}^{3+}+e^{-} \\
& \mathrm{Co}^{3+}+\mathrm{Fe}^{2+}(\text { ferrous }) \rightarrow \mathrm{Co}^{2+}+\mathrm{Fe}^{3+}(\text { ferric }) \\
& e^{-}+\mathrm{O}_{2} \rightarrow \mathrm{O}_{2}^{-*} \\
& \mathrm{~h}_{\mathrm{VB}}^{+}+\mathrm{H}_{2} \mathrm{O} \rightarrow \mathrm{H}^{+}+\mathrm{HO}^{*} \\
& \mathrm{O}_{2}^{-*}+\mathrm{H}^{+} \rightarrow \mathrm{HO}_{2}^{*} \rightarrow \rightarrow \mathrm{H}_{2} \mathrm{O}_{2}+\mathrm{O}_{2} \\
& \mathrm{H}_{2} \mathrm{O}_{2}+\mathrm{O}_{2}^{-*} \rightarrow \mathrm{HO}^{*}+\mathrm{HO}^{-}+\mathrm{O}_{2}
\end{aligned}
$$


$\mathrm{Co}^{3+}+\mathrm{HO}^{-} \rightarrow \mathrm{Co}^{2+}+\mathrm{HO}^{*}$

$\mathrm{O}_{2}^{-*}, \mathrm{HO}^{*}, \mathrm{HO}_{2}^{*}+\mathrm{CV} \rightarrow$ Degradation products of $\mathrm{CV}$

Kinetic parameters of zero-order, first-order and second-order rate equations for CV degradation in presence of $\mathrm{CoFe}_{2} \mathrm{O}_{4}$ nanoparticles were listed in Table 3. Fitting the data of photocatalytic activity test to $(\mathrm{C})-\mathrm{t}$ and for $\ln (\mathrm{Co} / \mathrm{C})-\mathrm{t}$ showed that neither first order nor second order kinetic models were succesful in representing the photodegradation kinetics of CV.

Table 3

Kinetic parameters of three different kinetic models.

\begin{tabular}{lll}
\hline Kinetic Model & Parameters & Value \\
\hline \multirow{2}{*}{ Zero-order } & $\mathrm{k}$ & $8.2 \mathrm{E}^{-4} \mathrm{mg} / \mathrm{L} . \mathrm{min}$ \\
& $\mathrm{R}^{2}$ & 0.9143 \\
\multirow{2}{*}{ First-order } & $\mathrm{k}_{1}$ & $0.00121 / \mathrm{min}$. \\
& $\mathrm{R}^{2}$ & 0.9458 \\
\hline \multirow{3}{*}{ Second-order } & $\mathrm{k}_{2}$ & $1.91 \mathrm{E}^{-3} \mathrm{~L} / \mathrm{mg} \cdot \mathrm{min}$ \\
& $\mathrm{C}_{\mathrm{o}}$ (experimental) & $0.95 \mathrm{mg} / \mathrm{L}$ \\
& $\mathrm{C}_{\mathrm{o}}$ (theory) & $0.82 \mathrm{mg} / \mathrm{L}$ \\
& $\mathrm{R}^{2}$ & 0.9855 \\
\hline
\end{tabular}

Second-order kinetic model was the best relationship that fits the degradation of $\mathrm{CV}$ by $\mathrm{CoFe}_{2} \mathrm{O}_{4}$ nanoparticles. Additionally, the theoretical concentration $\mathrm{C}_{\mathrm{o}}$ (theory) obtained by second-order model $(0.82 \mathrm{mg} / \mathrm{L})$ fit with the experimental value of $\mathrm{C}_{\mathrm{o}}$ (experimental) $(0.95 \mathrm{mg} / \mathrm{L})$ well. Briefly, it can be stated that the second-order kinetic model was the most acceptable model to describe the experimental kinetic data of $\mathrm{CV}$ photodegradation.

$\mathrm{CoFe}_{2} \mathrm{O}_{4}$ nanoparticles were also responsible from concentration dependent hemolysis ratios as shown by hemolysis assay (Fig. 7). Results were consistent because formation of ROS is considered as one of the main reasons of oxidative stress resulting lysis of erythrocytes.

\section{Conclusion}

$\mathrm{CoFe}_{2} \mathrm{O}_{4}$ nanoparticles were prepared by the co-precipitation method. Structural, magnetic and photocatalytic properties of cobalt ferrites were analyzed according to their chemical composition considering their biological properties. X-ray diffraction analysis exhibited a spinel cubic structure without secondary phases. Using the Scanning Electron Microscope, the morphology of $\mathrm{CoFe}_{2} \mathrm{O}_{4}$ nanoparticles was examined and it was observed that the particles did not have a complete shape because they were agglomerated. The direct gap energies of the $\mathrm{CoFe}_{2} \mathrm{O}_{4}$ nanoparticles were observed as $2.1 \mathrm{eV}$. S-shaped magnetic hysteresis loop shows a soft ferromagnetic behavior. The coercivity field and magnetic saturation values of the $\mathrm{CoFe}_{2} \mathrm{O}_{4}$ nanoparticles at room temperate were $483 \mathrm{Oe}$ and $60.39 \mathrm{emu} / \mathrm{g}$, respectively. Increasing intensity of absorption band at $408 \mathrm{~nm}$ and the precipitate showing a characteristic black color of heme-iron complexes were attributed to the strong oxidation of oxyhemoglobyn to methemoglobin. $\mathrm{CoFe}_{2} \mathrm{O}_{4}$ nanoparticles showed undesirable hemolytic effect in both $1 \mathrm{mg} / \mathrm{ml}$ and $5 \mathrm{mg} / \mathrm{ml}$ concentrations. Undesirable hemolytic effect of $\mathrm{CoFe}_{2} \mathrm{O}_{4}$ nanoparticles on human erythrocytes at both concentrations was attributed to the comparatively high amount of reactive oxygen species formed by $\mathrm{CoFe}_{2} \mathrm{O}_{4}$ nanoparticles. Photocatalytic properties of $\mathrm{CoFe}_{2} \mathrm{O}_{4}$ nanoparticles were investigated with three kinetic models. Among these, second-order kinetic model was found as the best relationship that fits the degradation of $\mathrm{CV}$ by $\mathrm{CoFe}_{2} \mathrm{O}_{4}$ nanoparticles. The theoretical concentration $\mathrm{C}_{\mathrm{o}}$ (theory) obtained by second-order model $(0.82 \mathrm{mg} / \mathrm{L}) \mathrm{fit}$ with the experimental value of $\mathrm{C}_{\mathrm{o}}$ (experimental) $(0.95 \mathrm{mg} / \mathrm{L})$.

\section{Acknowledgments}

This research was supported by the Research Fund of Bahcesehir University (BAU-BAP.2018.02.16), Istanbul.

\section{References}

1. G. Kandasamy, K. Kumar, Synergy between nanoparticles and breast cancer theranostics, Nanomedicines for Breast Cancer Theranostics (2020) 71-106

2. S. Nikazar, M. Barani, A. Rahdar, M. Zoghi, G.Z. Kyzas, Photo-and Magnetothermally Responsive Nanomaterials for Therapy, Controlled Drug Delivery and Imaging Applications, Chemistry Select, 5(40) (2020) 12590-12609.

3. Y. Wang, L. Zou, Z. Qiang, J. Jiang, Z. Zhu, J. Ren, Enhancing Targeted Cancer Treatment by Combining Hyperthermia and Radiotherapy Using Mn-Zn Ferrite Magnetic Nanoparticles, ACS Biomaterials Science \& Engineering, 6(6) (2020) 3550-3562.

4. D. Maity, A. Sudame, G. Kandasamy, Superparamagnetic Iron Oxide Nanoparticle-Based Drug Delivery in Cancer Therapeutics, Nanobiotechnology in Diagnosis, Drug Delivery, and Treatment (2020) 129-151.

5. A. Sutradhar, Effects of Buoyant and Saffman lift force on Magnetic Drug Targeting in Microvessel in the presence of inertia, Microvascular Research (2020) 104099. 
S.M. Dadfar, K. Roemhild, N.I. Drude, S. von Stillfried, R. Knüchel, F. Kiessling, T. Lammers, Iron oxide nanoparticles: Diagnostic, therapeutic and theranostic applications, Advanced drug delivery reviews, 138 (2019) 302-325.

7. M.C. Chapman, A.Y. Lee, J.H. Hayward, B.N. Joe, E.R. Price, Superparamagnetic iron oxide) sentinel node tracer injection: effects on Breast MRI Quality, Journal of Breast Imaging, 2(6) (2020) 577-582.

8. S. Kossatz, J. Grandke, P. Couleaud, A. Latorre, A. Aires, K. Crosbie-Staunton, M. Calero, Efficient treatment of breast cancer xenografts with multifunctionalized iron oxide nanoparticles combining magnetic hyperthermia and anti-cancer drug delivery, Breast Cancer Research, 17(1) (2015) 66. https://doi.org/10.1186/s13058-015-0576-1

9. N.P. Devi, M. Maisnam, Characterizations of Sol-Gel Synthesized and High Energy Ball Milled Spinel Nanoferrites: $\mathrm{MFe}_{2} \mathrm{O}_{4}(\mathrm{M}=\mathrm{Li}, \mathrm{Ni}, \mathrm{Zn}$, Mn) for Nanofluid Preparations, Integrated Ferroelectrics, 204(1) (2020) 133-141.

10. M.K. Satheeshkumar, E.R. Kumar, P. Indhumathi, C. Srinivas, M. Deepty, S. Sathiyaraj, N. Suriyanarayanan, D.L. Sastry, Structural, morphological and magnetic properties of algae/CoFe2O4 and algae/Ag-Fe-O nanocomposites and their biomedical applications, Inorganic Chemistry Communications, 111 (2020) 107578.

11. M. Deepty, S. Ch, P.N. Ramesh, N.K. Mohan, M.S. Singh, C.L. Prajapat, A. Verma, D.L. Sastry, Evaluation of structural and dielectric properties of $\mathrm{Mn}^{2+}$-substituted Zn-spinel ferrite nanoparticles for gas sensor applications. Sensors and Actuators B: Chemical (2020) 128127.

12. Y. Xu, Y. Ma, S. Xu, G. Zheng, Z. Dai, Diluted and undiluted monodispersed CoFe2O4 nanoparticles: the effects of post-annealing on magnetic properties, Journal of Materials Science, 50(13) (2015) 4486-4494. https://doi.org/10.1007/s10853-015-8997-X

13. S. Yáñez-Vilar, M. Sánchez-Andújar, C. Gómez-Aguirre, J. Mira, M.A. Señarís-Rodríguez, S. Castro-García, A simple solvothermal synthesis of $\mathrm{MFe}_{2} \mathrm{O}_{4} \quad(\mathrm{M}=\mathrm{Mn}$, Co and Ni) nanoparticles, Journal of Solid State Chemistry, 182(10) (2009) 2685-2690. https://doi.org/10.1016/j.jssc.2009.07.028

14. T.A. Tabish, M.N. Ashiq, M.A. Ullah, S. Iqbal, M. Latif, M. Ali, F. Iqbal, Biocompatibility of cobalt iron oxide magnetic nanoparticles in male rabbits, Korean Journal of Chemical Engineering, 33(7) (2016) 2222-2227. https://doi.org/10.1007/s11814-016-0043-4

15. D. Stanicki, L. Vander Elst, R.N. Muller, S. Laurent, D. Felder-Flesch, D. Mertz, O. Ersen, Iron-oxide nanoparticle-based contrast agents. In Contrast Agents for MRI (2017) 318-447.

16. G.X. Wang, C.J. Liu, Y.M. Zhang, H.F. Peng, X. Wang, Characterization of Nanosize Mn-Zn Ferrites Coated with Citric Acid, In Advanced Materials Research, 391 (2012) 835-838.

17. K. Laznev, D. Tzerkovsky, K. Kekalo, G. Zhavnerko, V. Agabekov, IEEE. Trans. Magnet., 49 (2013) 425.

18. K. Shahzad, S. Mushtaq, M. Rizwan, W. Khalid, M. Atif, F.U. Din, Z. Ali, Field-controlled magnetoelectric core-shell CoFe2O4@ BaTiO3 nanoparticles as effective drug carriers and drug release in vitro, Materials Science and Engineering: C, 119 (2020) 111444

19. B. Cai, M. Zhao, Y. Ma, Z. Ye, J. Huang, Bioinspired formation of 3D hierarchical CoFe2O4 porous microspheres for magnetic-controlled drug release, ACS applied materials \& interfaces, 7(2) (2015) 1327-1333. https://doi.org/10.1021/am507689a

20. N.A. Oladoja, E.T. Anthony, I.A. Ololade, T.D. Saliu, G.A. Bello, Self-propagation combustion method for the synthesis of solar active Nano Ferrite for Cr (VI) reduction in aqua system. Journal of Photochemistry and Photobiology A: Chemistry, 353 (2018) $229-239$.

21. L.A. Frolova, O.V. Khmelenko, The Study of Co-Ni-Mn Ferrites for the Catalytic Decomposition of 4-Nitrophenol. Catalysis Letters, (2020) $1-12$.

22. M. Rani, U. Shanker, A.K. Chaurasia, Catalytic potential of laccase immobilized on transition metal oxides nanomaterials: degradation of alizarin red S dye, Journal of environmental chemical engineering, 5(3) (2017) 2730-2739. https://doi.org/10.1016/j.jece.2017.05.026

23. C. He, Z.Q. Shi, L. Ma, C. Cheng, C.X. Nie, M. Zhou, C.S. Zhao, Graphene oxide based heparin-mimicking and hemocompatible polymeric hydrogels for versatile biomedical applications, Journal of Materials Chemistry B, 3(4) (2015) 592-602. https://doi.org/10.1039/C4TB01806K H.C. Fang, Z. Yang, C.K. Ong, Y. Li, C.S. Wang, Preparation and magnetic properties of (Zn-Sn) substituted barium hexaferrite nanoparticles for magnetic recording, J. Magn. Magn Mater. 187 (1998) 129-135. https://doi.org/10.1016/S0304-8853(98)00139-5

25. M. Amiri, A. Akbari, M. Ahmadi, A. Pardakhti, M. Salavati-Niasari, Synthesis and in vitro evaluation of a novel magnetic drug delivery system; proecological method for the preparation of $\mathrm{CoFe}_{2} \mathrm{O}_{4}$ nanostructures, Journal of Molecular Liquids, 249 (2018) 1151-1160. https://doi.org/10.1016/j.molliq.2017.11.133

26. Y. Oh, M.S. Moorthy, P. Manivasagan, S. Bharathiraja, J. Oh, Magnetic hyperthermia and pH-responsive effective drug delivery to the subcellular level of human breast cancer cells by modified $\mathrm{CoFe}_{2} \mathrm{O} 4$ nanoparticles, Biochimie, 133 (2017) 7-19. https://doi.org/10.1016/j.biochi.2016.11.012

27. S. Anandan, T. Selvamani, G.G. Prasad, A.M. Asiri, J.J. Wu, Magnetic and catalytic properties of inverse spinel CuFe $\mathrm{O}_{4}$ nanoparticles, Journal of Magnetism and Magnetic Materials, 432 (2017) 437-443. https://doi.org/10.1016/j.jmmm.2017.02.026

28. X. Dong, B. Ren, Z. Sun, C. Li, X. Zhang, M. Kong, D.D. Dionysiou, Monodispersed CuFe $\mathrm{O}_{4}$ nanoparticles anchored on natural kaolinite as highly efficient peroxymonosulfate catalyst for bisphenol A degradation, Applied Catalysis B: Environmental, 253 (2019) $206-217$. https://doi.org/10.1016/j.apcatb.2019.04.052

29. N. Verimli, A. Demiral, H. Yılmaz, M. Çulha, S.S. Erdem, Design of Dense Brush Conformation Bearing Gold Nanoparticles as Theranostic Agent for Cancer, Applied biochemistry and biotechnology, 189(3) (2019) 709-728. https://doi.org/10.1007/s12010-019-03151-6

30. T.A. Tabish, M.N. Ashiq, M.A. Ullah, S. Iqbal, M. Latif, M. Ali, F. Iqbal, Biocompatibility of cobalt iron oxide magnetic nanoparticles in male rabbits, Korean Journal of Chemical Engineering, 33(7) (2016) 2222-2227. https://doi.org/10.1007/s11814-016-0043-4

31. S.Y. Srinivasan, K.M. Paknikar, D. Bodas, V. Gajbhiye, Applications of cobalt ferrite nanoparticles in biomedical nanotechnology, Nanomedicine, 13(10) (2018) 1221-1238. https://doi.org/10.2217/nnm-2017-0379

32. M.C. Morán, A.F. Jorge, M.P. Vinardell, Sustainable DNA release from chitosan/protein based-DNA gel particles, Biomacromolecules, 15(11) (2014) 3953-3964. https://doi.org/10.1021/bm501039g

33. ISO 10993-4. Selection of tests for interaction with blood. International Standard Organization: Geneva, Switzerland, 1992.

34. D. Zimmerman, J. Dienes, O. Abdulmalik, J.J. Elmer, Purification of diverse hemoglobins by metal salt precipitation, Protein expression and purification, 125 (2014) 74-82. https://doi.org/10.1016/j.pep.2015.09.006

35. C.S. Silva, C. Moutinho, A. Ferreira da Vinha, C. Matos, Trace Minerals in Human Health: Iron, Zinc, Copper, Manganese and Fluorine, International Journal of Science and Research Methodology, 13 (2019) 57-80.

36. Galanis, A. Karapetsas, R. Sandaltzopoulos, Metal-induced carcinogenesis, oxidative stress and hypoxia signaling, Mutation research/Genetic toxicology and environmental mutagenesis, 674(1-2) (2009) 31-35. https://doi.org/10.1016/j.mrgentox.2008.10.008

37. A. Pichert, J. Arnhold, Interaction of the chlorite-based drug WF10 and chlorite with hemoglobin, methemoglobin and ferryl hemoglobin, Archives of biochemistry and biophysics, 585 (2015) 82-89. https://doi.org/10.1016/j.abb.2015.09.009

38. H.M. Shen, G.Y. Zhu, W.B. Yu, H.K. Wu, H.B. Ji, H.X. Shi, Y.B. She, Surface immobilization of $\beta$-cyclodextrin on hybrid silica and its fast adsorption performance of p-nitrophenol from the aqueous phase, Rsc Advances, 5(103) (2015) 84410-84422.

39. A.C. Gradinaru, G. Solcan, M.C. Spataru, L.D. Hritcu, L.C. Burtan, C. Spataru, The Ecotoxicology of Heavy Metals from Various Anthropogenic Sources and Pathways for their Bioremediation, Revista De Chimie, 70(7) (2019) 2556-2560.

40. S.C. Shen, A.B. Ley, Methemoglobin formation in human blood by cobalt in vitro, The Journal of clinical investigation, 33(11) (1954) 15601566.

41. M. Adam, S. Murugavel, A. Bugyei-Twum, T. Narang, S. Jain, Y. Pan, K.K. Singh, BRCA2 is a Novel Regulator of Endothelial Cell Function and Apoptosis Following Oxidative Stress, Atherosclerosis Supplements, 32 (2018) 110

42. C. Fanelli, R. Zatz, Linking oxidative stress, the renin-angiotensin system, and hypertension, Hypertension. 57 (2011) $373-374$. https://doi.org/10.1161/HYPERTENSIONAHA.110.167775 
43. M.G. Nair, M. Nirmala, K. Rekha, A. Anukaliani, Structural, optical, photo catalytic and antibacterial activity of ZnO and Co doped ZnO nanoparticles, Materials Letters, 65(12) (2011) 1797-1800.

44. H. Tong, S. Ouyang, Y. Bi, N. Umezawa, M. Oshikiri, J. Ye, Nano-photocatalytic materials: possibilities and challenges, Advanced materials, 24(2) (2012) 229-251.

45. G. Li, C. Guo, M. Yan, S. Liu, CsxWO3 nanorods: Realization of full-spectrum-responsive photocatalytic activities from UV, visible to nearinfrared region, Applied Catalysis B: Environmental, 183 (2016) 142-148. 
Figures

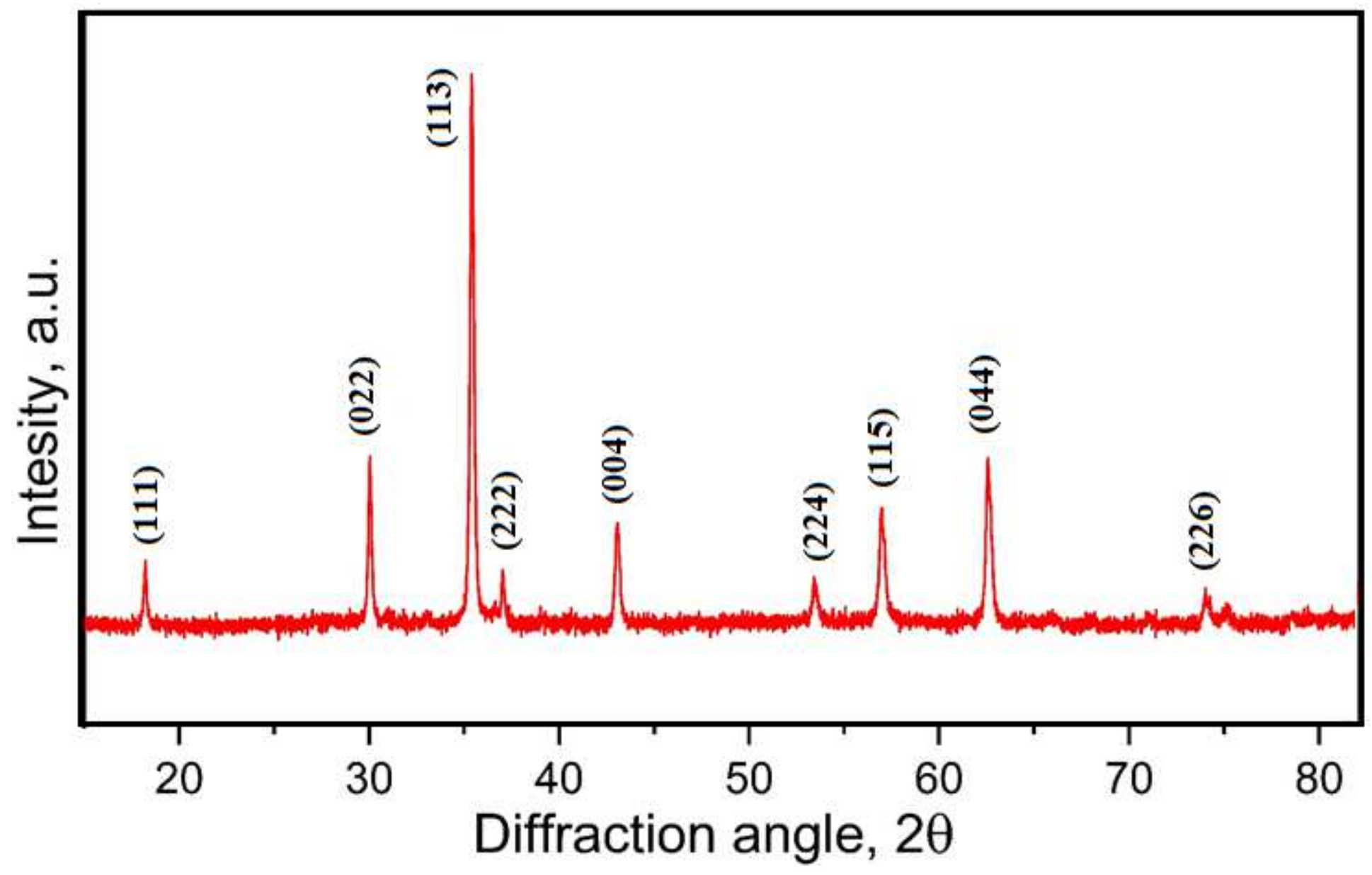

Figure 1

X-ray diffraction patterns of CoFe204 ferrite nanoparticles. 


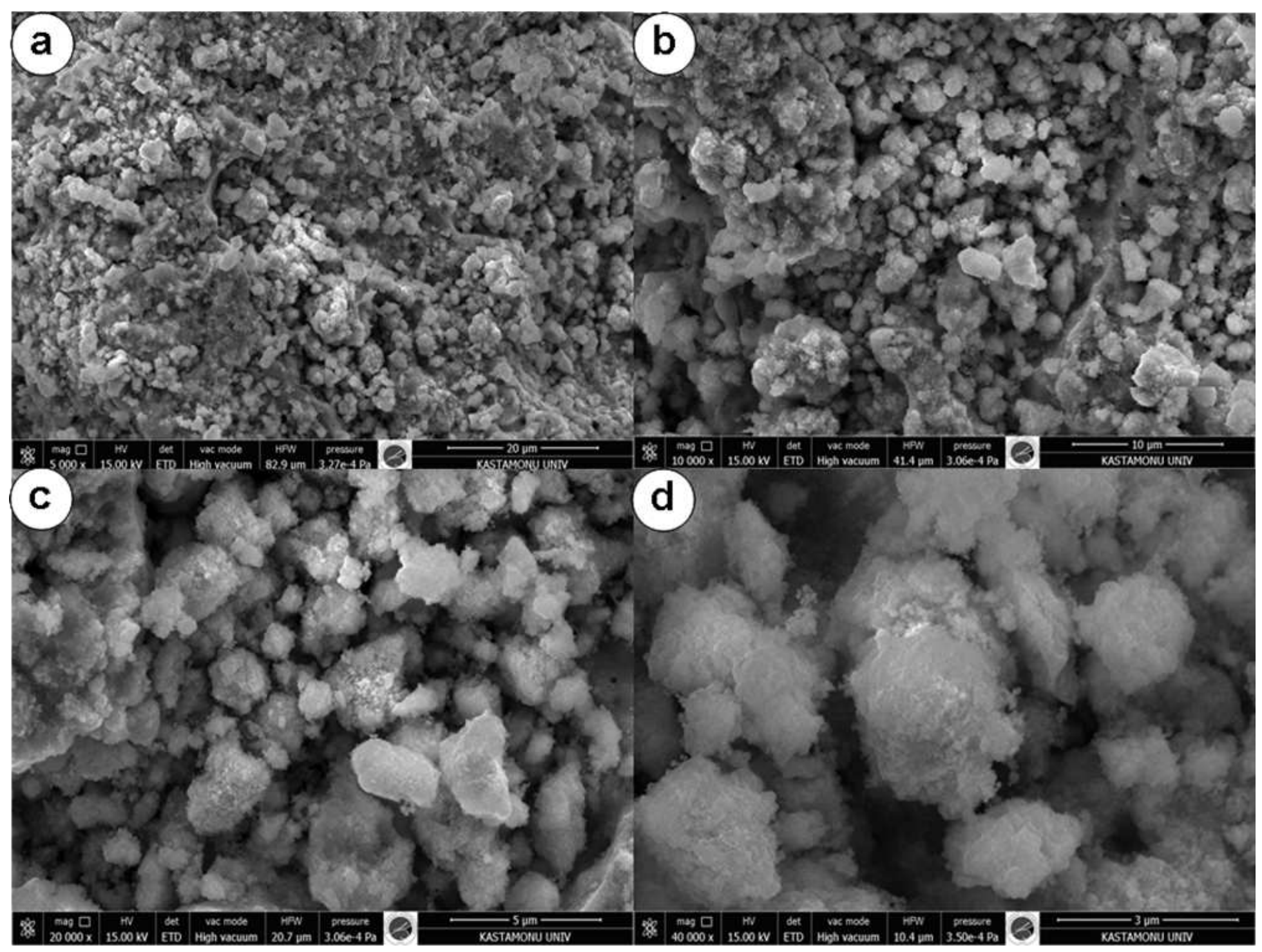

Figure 2

SEM images of CoFe2O4 nanoparticles for $20,10,5$ and $3 \mu \mathrm{m}$ magnifications in (a), (b), (c) and (d), respectively. 


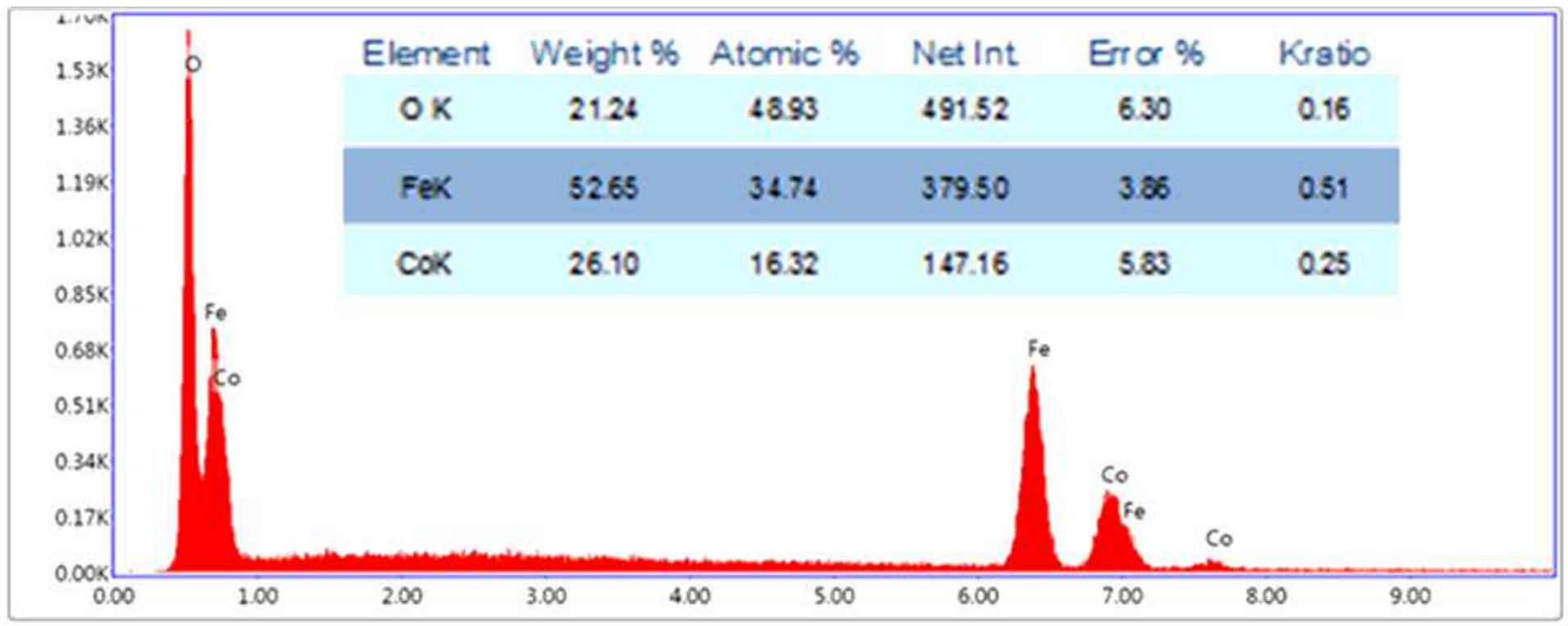

Lsec: 26.60 Cnts $0.000 \mathrm{keV}$ Det: Octane Pro Det

Figure 3

EDS graph of CoFe2O4 nanoparticles.

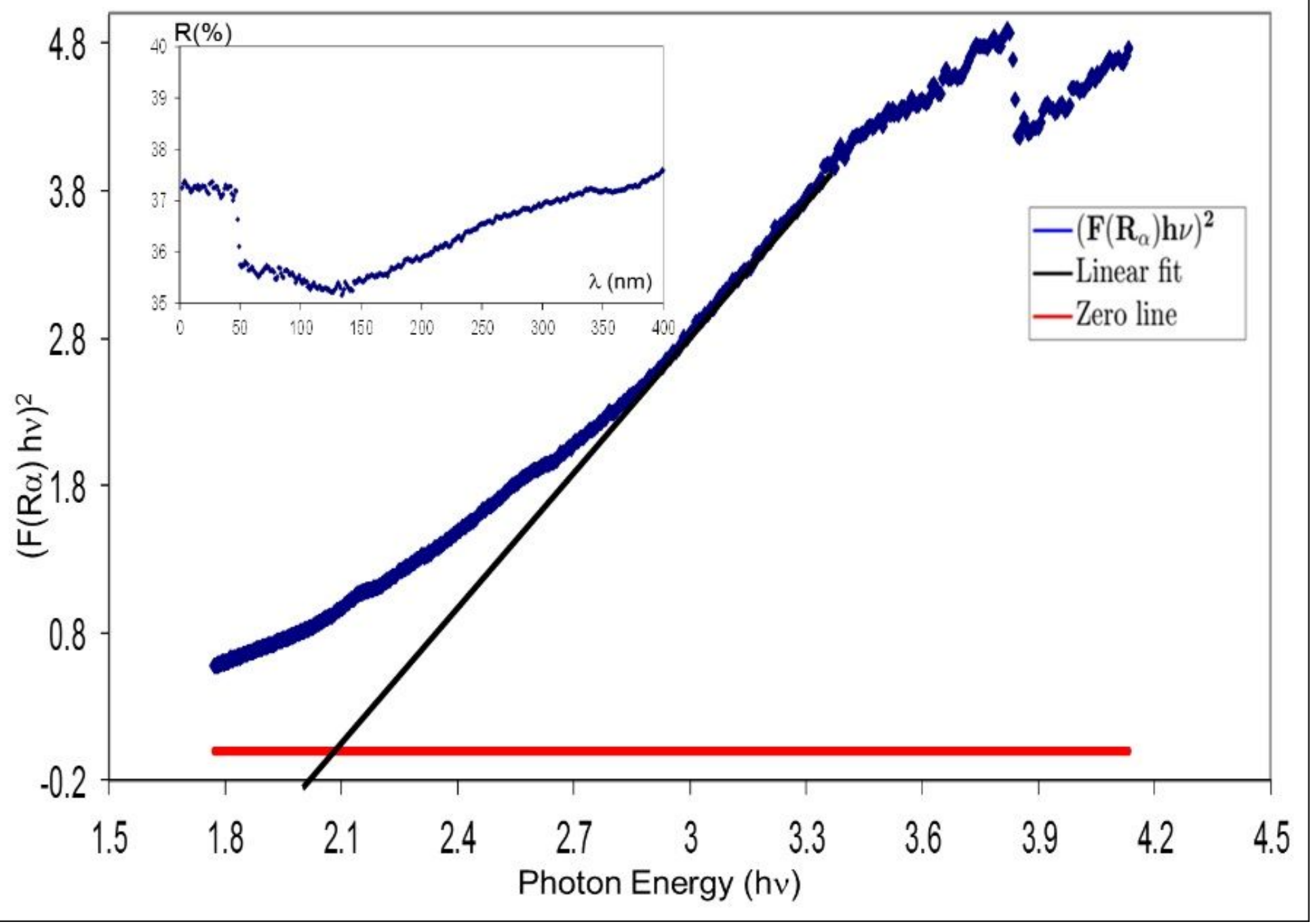


Figure 4

The plots of $(F(R a) h v)^{\wedge} 2$ as a function of photon energy (hv) and the linear fit for the CoFe2O4 nanoparticles.

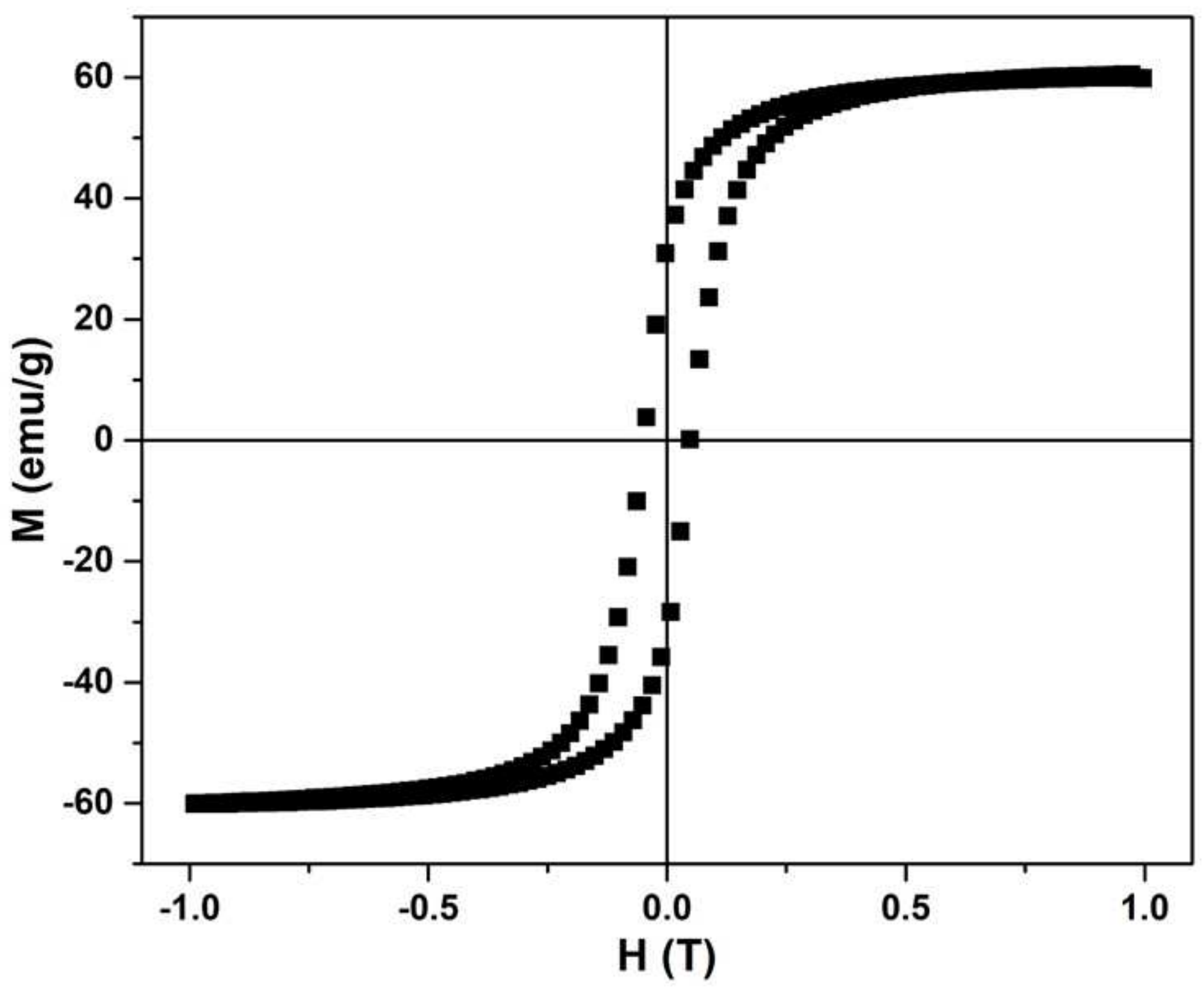

Figure 5

$\mathrm{M}-\mathrm{H}$ curves measured at $\mathrm{T}=300 \mathrm{~K}$ for CoFe204 nanoparticles. 


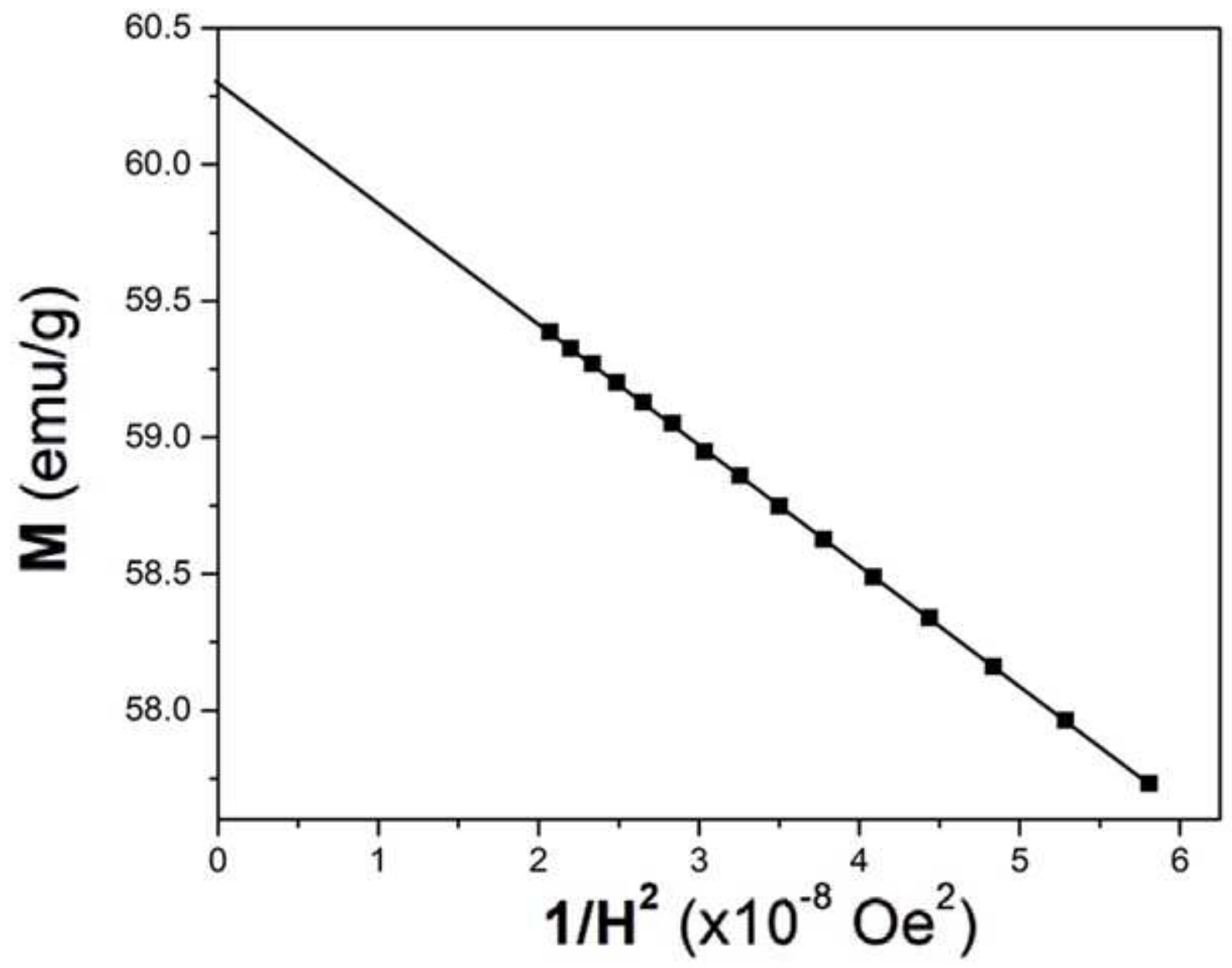

Figure 6

Plots of $\mathrm{M}$ vs. $1 / \mathrm{H} 2$ obtained on representative samples at $\mathrm{T}=300 \mathrm{~K}$. 


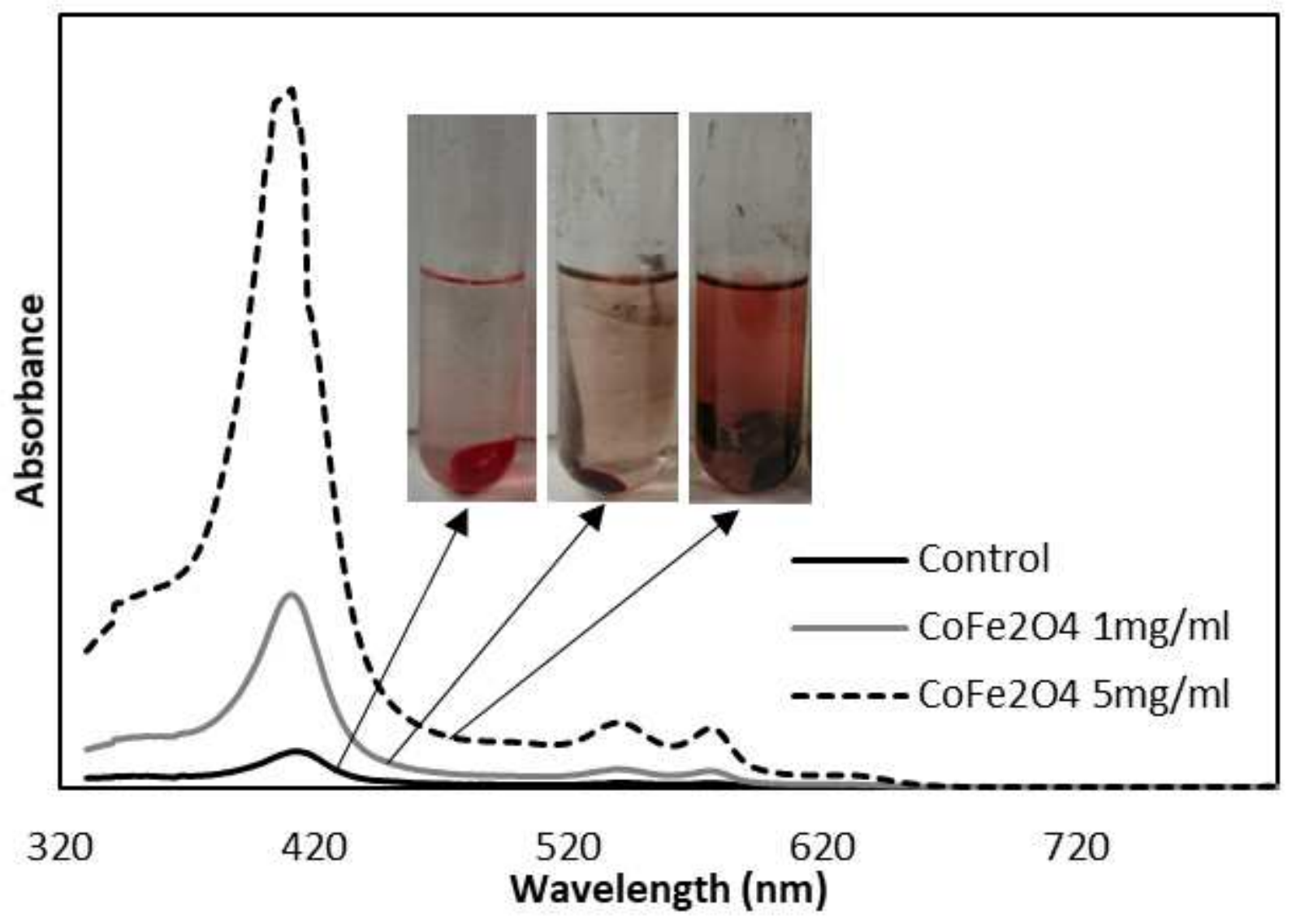

Figure 7

UV-vis spectra of erythrocyte suspensions treated with PBS alone (control) and CoFe2O4 nanoparticles with two different concentrations. The inset shows blood supernatant after centrifugation.
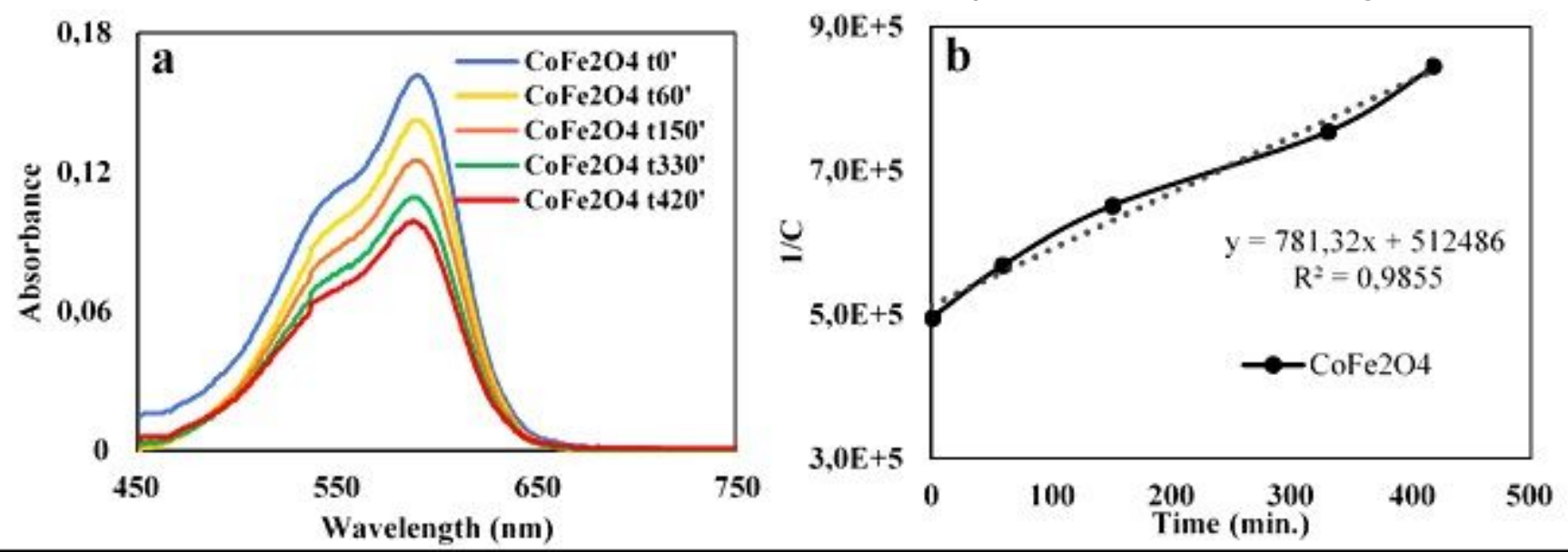

Figure 8

UV-vis spectra of CV as a function of time in presence of (a) CoFe2O4 under $254 \mathrm{~nm}$ irradiation and (b) second order kinetic plot for photocatalytic degradation of CV over CoFe2O4 nanoparticles. 